\title{
ARTIGO
}

\section{ECONOMICIDADE, EFICIÊNCIA E TRANSPARÊNCIA NAS COMPRAS PÚBLICAS VIA PREGÃO ELETRÔNICO: ESTUDO DE CASO DOS PREGÕES ELETRÔNICOS 42/2012 E 32/2013 REALIZADOS PELO IFPR - CAMPUS ASSIS CHATEAUBRIAND ${ }^{1}$}

\author{
Helton Jaques Albiero \\ Marcelo Rodrigues da Silva
}

\begin{abstract}
RESUMO
O presente artigo aborda a preocupação com os gastos públicos, principalmente com os princípios basilares da economicidade, eficiência e transparência, no Instituto Federal do Paraná, focando especificamente dois certames licitatórios, modalidade Pregão Eletrônico Sistema de Registro de Preços (SRP), tendo como objeto a aquisição de mobiliário em geral para os diversos campi da Instituição, realizados pelo IFPR - Campus Assis Chateaubriand em 2012 e 2013. Através de dados documentais e pesquisa de campo, realizada por meio de questionário eletrônico encaminhado aos gestores internos da Instituição e licitantes envolvidos nestes certames objetivou-se verificar a existência destes princípios basilares nos dois certames elencados. O princípio da economicidade foi demonstrado através do estudo comparativo entre os valores estimados para as referidas aquisições e o real valor da contratação, que estabeleceu um desconto de 42,64\% em 2012 e 37,64\% em 2013. Observouse também que $85 \%$ dos fornecedores tomou conhecimento destes dois pregões eletrônicos por outros meios que não o Diário Oficial da União e Jornais, merecendo o princípio da publicidade uma reavaliação por parte da instituição. De forma geral, é possível avaliar de maneira positiva as realizações destes pregões eletrônicos quanto aos princípios elencados.
\end{abstract}

Palavras-chave: Pregão Eletrônico. Economicidade. Eficiência. Transparência. Compras Públicas.

\section{INTRODUÇÃO}

Motivo de assunto e calorosas críticas estampadas diariamente em noticiários, tanto na mídia falada quanto na mídia escrita, além de amplamente discutido pela sociedade, o tema compras públicas tem sido frequentemente questionado quanto ao respeito e a existência de

\footnotetext{
${ }^{1}$ Como citar este artigo: ALBIERO, Helton Jaques; SILVA, Marcelo Rodrigues da. Economicidade, eficiência e transparência nas compras públicas via pregão eletrônico: estudo de caso dos pregões eletrônicos 42/2012 e 32/2013 realizados pelo IFPR - Campus Assis Chateaubriand. ForScience: revista científica do IFMG, Formiga, v.6, n. 1, e00275, jan./jun. 2018.

2 Autor para correspondência: Helton Jaques Albiero, IFPR - Campus Assis Chateubriand, e-mail: helton.albiero@ifpr.edu.br.
} 
seus princípios legalmente estabelecidos, principalmente os princípios da economicidade, da eficiência e da transparência.

A eficiência, para a Administração pública, é o ato de atender uma demanda social de maneira ampla e satisfatória, utilizando meios adequados e o menor dispêndio econômico possível, almejando o bem comum. Neste contexto, a eficiência é derivada da economicidade, que por sua vez significa o ato de gerar economia, ou seja, administrar de forma correta e responsável o recurso financeiro destinado a aquisição de um bem ou serviço para o atendimento das necessidades da maioria da sociedade de maneira desejável, proporcionando assim uma otimização da relação custo-benefício. Entretanto, a demonstração dos gastos realizados pela Administração pública para se atingir a eficiência em uma política pública, seja ela qual for, torna-se fundamental e obrigatória. Sendo assim, é principalmente através da transparência destes gastos públicos que se estabelece e se comprova a boa gestão dos recursos públicos, e que, consequentemente, culminam por demonstrar a eficiência da ação em prol do bem comum e de maneira econômica.

Portanto, tendo como principal preocupação a boa gestão dos recursos públicos, este estudo busca demonstrar como os princípios da eficiência, da economicidade e da transparência podem ser observados e mensurados na realização dos pregões eletrônicos para a aquisição de móveis para as diversas Unidades do Instituto Federal do Paraná nos anos de 2012 e 2013, especificamente nos Pregões Eletrônicos - Sistema de Registro de Preços (SRP) 42/2012 e 32/2013. Esta análise certamente servirá como parâmetro para a avaliação, adequação ou aperfeiçoamento de outros futuros procedimentos licitatórios da Instituição.

\section{COMPRAS PÚBLICAS E PREGÃO ELETRÔNICO}

Com o intuito de adequar, de forma legal, as aquisições de bens e serviços por parte da Administração Pública, em 1988 a Constituição da República Federativa do Brasil, em seu artigo 37 estabeleceu:

Art. 37. A administração pública direta e indireta de qualquer Poderes da União, dos Estados, do Distrito Federal e dos Municípios obedecerá aos princípios da legalidade, impessoalidade, moralidade, publicidade e eficiência e, também ao seguinte: [...] XXI. Ressalvados os casos especificados na legislação, as obras, serviços, compras e alienações serão contratados mediante processo de licitação pública que assegure igualdade de condições a todos os concorrentes, com cláusulas que estabeleçam obrigações de pagamento, mantidas as condições efetivas da proposta, nos termos da lei, o qual somente permitirá as exigências de qualificação técnica e econômica indispensáveis à garantia do cumprimento das obrigações. (BRASIL, 1988)

ForSci.: r. cient. IFMG, Formiga, v. 6, n. 1, e00275, jan./jun. 2018. 
Posteriormente, em 21 de junho de 1993, com a função de regulamentar este art. 37, inciso XXI da Constituição Federal, foi sancionada a Lei $n^{\circ} 8.666$ ordenando que:

Art. $1^{\circ}$. Esta lei estabelece normas gerais sobre licitações e contratos administrativos pertinentes a obras, serviços, inclusive de publicidade, compras, alienações e locações no âmbito dos Poderes da União, dos Estados, do Distrito Federal e dos Municípios. Parágrafo Único. Subordina-se ao regime desta Lei, além dos órgãos da administração direta, os fundos especiais, as autarquias, as fundações públicas, as empresas públicas, as sociedades de economia mista e demais entidades controladas direta ou indiretamente pela União, Estados, Distrito Federal e Municípios. (BRASIL, 1993)

Na constante busca pela atualização necessária da legislação, em 04 de maio de 2000, foi institucionalizado, através da Medida Provisória n 2.026 (BRASIL, 2000), o pregão. Esta Medida Provisória, renumerada e reeditada por várias vezes, deu origem, em 08 de agosto de 2000, ao Decreto $\mathrm{n}^{\circ} 3.555$ (BRASIL, 2000), aprovando a criação de uma nova modalidade de licitação denominada pregão, para a aquisição de bens e serviços comuns no âmbito da União. Estabelecendo ainda que, além da Administração Federal direta, os fundos especiais, as autarquias, as fundações, as empresas públicas, as sociedades de economia mista e as demais entidades controladas direta ou indiretamente pela União sejam subordinadas ao regime deste Decreto.

Na sequência cronológica da legislação, em 17 de julho de 2002, através da Lei $\mathrm{n}^{\circ} 10.520$ (BRASIL, 2002), fica instituída, no âmbito da União, Estados, Distrito Federal e Municípios, nos termos do mesmo Art. 37, inciso XXI, da Constituição Federal, a possibilidade da modalidade de licitação denominada pregão, em sua forma tradicional, para a aquisição de bens e serviços comuns:

Art. $1^{\circ}$. Para a aquisição de bens e serviços comuns, poderá ser adotada a licitação na modalidade de pregão, que será regida por esta Lei. Parágrafo Único. Consideram-se bens e serviços comuns, para os fins e efeitos deste artigo, aqueles cujos padrões de desempenho e qualidade possam ser objetivamente definidos pelo edital, por meio de especificações usuais no mercado. (BRASIL, 2002)

Tal modalidade licitatória viabilizou-se notoriamente. Aliada à popularização das ferramentas tecnológicas, principalmente $\mathrm{o}$ acesso à internet por parte das empresas, modernizou os procedimentos licitatórios novamente. $O$ art. $2^{\circ}$, §1 da Lei $n^{\circ} 10.520 / 2002$ já permitia a utilização de recursos de tecnologia da informação para a sua realização, porém 
exigia uma legislação específica que veio a ser decretada em 31 de maio de 2005 através do Decreto ${ }^{\circ} 5.450$ (BRASIL, 2005), que determina em seu art. $2^{\circ}$ :

Art. $2^{\circ}$. O pregão, na forma eletrônica, como modalidade de licitação do tipo menor preço, realizar-se-á quando a disputa pelo fornecimento de bens ou serviços comuns for feita à distância em sessão pública, por meio de sistema que promova a comunicação pela internet. (BRASIL, 2005)

A questão da publicidade presente neste Decreto é destacada como de cabal importância por Figueiredo (2004) a partir do entendimento que todos os mecanismos de garantias atribuídos aos administrados, quer sejam individuais ou coletivos, dependem de ampla publicidade.

Todo este regramento apontado veio a ser complementado em 05 de agosto de 2005, com o Decreto $\mathrm{n}^{\circ} 5.504$ (BRASIL, 2005), que estabeleceu, legalmente, a obrigatoriedade, desde que tecnicamente viável, da utilização da modalidade pregão, preferencialmente na sua forma eletrônica, para todas as licitações realizadas pelos entes federativos da União e que sejam custeadas através de transferências voluntárias de recursos públicos advindos dela, com vista às aquisições e/ou contratações de bens e serviços comuns.

\section{OS PRINCÍPIOS DA ECONOMICIDADE, EFICIÊNCIA E TRANSPARÊNCIA}

Considerando que a Administração Pública, tal qual uma empresa privada, também carece de suprimentos que lhe possibilitem manutenção da continuidade da prestação de serviços para seus usuários, Bernardi (2012), relaciona a função primordial de compras com a continuidade das atividades operacionais da empresa.

Conforme o mesmo autor, quando se refere a compras, "têm como fatores críticos minimizar os custos, manter padrões de qualidade e evitar o desperdício, observando os aspectos essenciais de integridade e controle nas funções e nas etapas do processo de compras". (BERNARDI, 2012, p. 209)

Neste contexto, quando se refere às aquisições de bens e contratação de serviços, a Administração Pública, além de observar os fatores críticos apontados, tem a necessidade de respeitar todos os preceitos da legislação vigente, de maneira a atingir a função primordial de compras, que é manter a continuidade das atividades operacionais.

Em uma análise de empreendedorismo, tanto na Administração Pública quanto na empresa privada, são necessários vários princípios norteadores, dentre estes, o planejamento 
se torna fundamental. Assim, conforme ensina Chiavenato (2004, p. 152), “O planejamento é a primeira das funções administrativas e é a que determina antecipadamente quais são os objetivos a serem atingidos e como alcançá-los"

Neste sentido, segundo Stadler (2010), o processo de planejar tem a função de visualizar um cenário futuro considerando uma coleta de informações do presente, que nortearão objetivos a médio e longo prazo, sendo que a tomada de decisão para estes objetivos não deve ser baseada no improviso.

Para Araújo e Rodrigues (2012 apud PEREIRA; SPINK, 2006), para que se consiga transformar o aparato público brasileiro em uma nova gerência pública, tendo como objetivo a racionalização da gestão pública e a implantação de uma visão mais econômica, se faz necessário a introdução de noções de qualidade, produtividade e também responsabilidade dos funcionários, na Administração Pública.

De acordo com Moraes (2002), o princípio da eficiência impõe a Administração Pública e a seus agentes, a persecução do bem comum, evitando desperdícios e garantindo melhor rentabilidade social, através de suas competências, com imparcialidade, neutralidade, transparência, de forma eficaz e participativa, sem burocracia e sempre com qualidade, primando pela adoção dos critérios legais e morais necessários para a melhor utilização possível dos recursos públicos. Para ele, o administrador público precisa ser eficiente e exercer suas atividades respeitando a igualdade de todos perante a lei, a objetividade e a imparcialidade.

Oportunamente, quanto ao princípio da eficiência, Di Pietro (1998, p. 73-74) comenta: "impõe ao agente público um modo de atuar que produza resultados favoráveis à consecução dos fins que cabem ao Estado alcançar", advertindo, porém, que "a eficiência é princípio que se soma aos demais princípios impostos à Administração, não podendo sobrepor-se a nenhum deles, especialmente ao da legalidade, sob pena de sérios riscos à segurança jurídica e ao próprio Estado de Direito".

Desta maneira, não há de se negar que a eficiência e a economia nas compras públicas passam a estar intimamente ligadas, e em conjunto com a obrigatoriedade da aplicação de tais princípios surge o pregão em sua forma eletrônica que, por consequência, faz surgir a transparência quanto à boa gestão dos recursos públicos, motivo de preocupação tanto por parte dos gestores envolvidos quanto da população em geral, pois o montante gasto nestas execuções é fruto de recolhimentos tributários que retornarão em forma de serviços de boa qualidade aos cidadãos. 


\section{METODOLOGIA}

Do ponto de vista metodológico este estudo de caso se constitui em uma pesquisa de campo, tipo exploratória, com a utilização de estudos exploratório-descritivos combinados.

Conceitualmente, conforme ensina Yin (2015, p. 4), “[...] um estudo de caso permite que os investigadores foquem um "caso" e retenham uma perspectiva holística e do mundo real como no estudo dos ciclos individuais de vida, o comportamento dos pequenos grupos, os processos organizacionais e administrativos, [...]".

De acordo com Marconi e Lakatos (2003, p. 186), a pesquisa de campo, "consiste na observação de fatos e fenômenos tal como ocorrem espontaneamente, na coleta de dados a eles referentes e no registro de variáveis que se presume relevantes, para analisá-los”. Desta forma o presente trabalho caracteriza-se como uma pesquisa de campo, pelo fato de considerar a análise documental direta realizada a partir de documentos do Instituto Federal do Paraná - Campus Assis Chateaubriand, responsável pela realização dos certames licitatórios em análise. Ainda, quanto à tipificação desta investigação, trata-se de uma pesquisa de campo do tipo exploratória, pois conforme nos ensinam as mesmas Marconi e Lakatos (2003, p. 188), possui a "tripla finalidade de desenvolver hipóteses, aumentar a familiaridade do pesquisador com um ambiente, fato ou fenômeno, para a realização de uma pesquisa futura mais precisa ou modificar e clarificar conceitos". Por sua vez, esta pesquisa de campo exploratória, utiliza-se de estudos exploratório-descritivos combinados, obtidos através da pesquisa bibliográfica dos regramentos estabelecidos através da legislação vigente dos certames licitatórios, questionários, comparativos documentais e demais estudos publicados.

Sendo assim, o artigo inicia-se com o levantamento das principais normas legais e vigentes nas quais as compras de bens e serviços devem ser balizadas. Através desta análise documental à legislação pertinente, se traça a evolução cronológica do arcabouço jurídico referente ao processo das compras públicas, e da obrigatoriedade da sua observação por parte dos servidores públicos da União, dos Estados, do Distrito Federal e dos Municípios.

Posteriormente, a pesquisa sistemática analisa comparativamente os Pregões Eletrônicos 42/2012 e 32/2013 do Instituto Federal do Paraná, ambos visando aquisições de mobiliários em geral para todos os campi da Instituição, realizados respectivamente nos anos 2012 e 2013 pelo Campus Assis Chateaubriand. O comparativo destes dados, apontando as mais importantes variações, teve como foco comprovar a existência dos princípios da economicidade e da eficiência na realização nestes certames licitatórios. 
Finalizando o estudo, foram analisadas as respostas do questionário encaminhado via internet para os fornecedores que participaram dos pregões eletrônicos em questão, e também aos servidores públicos da Instituição envolvidos nos processos de aquisições destes produtos. Este questionário, encaminhado entre os dias 01 de outubro e 07 de outubro de 2014, coletou dados de 14 Unidades da Instituição e de 20 fornecedores que fizeram, no mínimo, a retirada do edital de um dos certames licitatórios motivo desta pesquisa.

\section{COMPARAÇÃO DOS PREGÕES ELETRÔNICOS 42/2012 e 32/2013}

Através da análise dos dados coletados junto à Pró Reitoria de Administração do Instituto Federal do Paraná, os pregões eletrônicos 42/2012 e 32/2013 realizados pelo Campus Assis Chateaubriand, ambos tendo como objeto a aquisição de móveis em geral para as diversas Unidades da Instituição, formulou-se a tabela abaixo onde é possível a verificação dos principais argumentos que poderão comprovar a existência dos princípios economicidade e eficiência.

Tabela 1 - Comparativo dos pregões eletrônicos 42/2012 e 32/2013

\begin{tabular}{lcc}
\hline Pregão Eletrônico & $\mathbf{4 2 / 2 0 1 2}$ & $\mathbf{3 2 / 2 0 1 3}$ \\
\hline Data do Certame & 29 de outubro de 2012 & 25 de novembro de 2013 \\
Objeto da Licitação & Mobiliário em Geral & Mobiliário em Geral \\
Número do Processo & $23411.002257 / 2012-10$ & $23411.001639 / 2013-07$ \\
Itens Licitados & 69 & 106 \\
Montante geral dos Itens & 29.060 & 21.264 \\
Itens cancelados & 2 & 6 \\
Montante dos itens cancelados & 280 & 435 \\
Resposta - Impugnações & 2 & 1 \\
Resposta - Recursos & - & $\mathrm{R} \$ 7.926 .450,66$ \\
Valor Estimado do Certame & $\mathrm{R} \$ 8.459 .147,15$ & $\mathrm{R} \$ 4.943 .084,73$ \\
Valor Contratado & $\mathrm{R} \$ 4.851 .782,75$ & $37,64 \%$ \\
Percentual de desconto obtido & $42,64 \%$ & - \\
\hline
\end{tabular}

Fonte: Elaborado pelo autor a partir de dados do Instituto Federal do Paraná - PROAD/DA.

O planejamento realizado pelos gestores, pré-requisito ideal e adequado para se chegar ao montante da estimativa das demandas que serão adquiridas no decorrer de cada exercício financeiro em questão, foi de fundamental importância para o acontecimento destes certames ForSci.: r. cient. IFMG, Formiga, v. 6, n. 1, e00275, jan./jun. 2018. 
licitatórios na Instituição. O alto valor estimado destes certames tornou primordiais os princípios da eficiência e principalmente da economicidade, uma vez que o bom uso do recurso público envolvido nestas aquisições poderá e deverá ser questionado a qualquer instante, tanto pelos órgãos de controle quanto pela sociedade em geral, pois somente através do princípio da transparência, ou seja, da publicidade de seus atos, é que a sociedade toma conhecimento da execução e da gestão destes recursos, exercendo a função de auditora destes gastos públicos.

O valor estimado para as aquisições, calculados através da soma dos preços médios orçados junto a três diferentes fornecedores para cada um dos itens licitados, de acordo com o estabelecido na legislação, tem a função de balizar e informar o preço máximo que a Instituição poderá desembolsar nestas aquisições. O somatório dos valores a ser gasto com cada item compõe o valor total a ser gasto pela Instituição na aquisição de móveis em geral, nos respectivos exercícios financeiros. Isto significa dizer que este seria o valor de mercado, a ser gasto conjuntamente por todas as Unidades do IFPR, para adquirir os móveis de seu interesse e para a organização mobiliária de seu Campus, no mercado varejista, ou seja, sem descontos. Com a utilização da ferramenta tecnológica denominada pregão eletrônico, que possibilita a participação virtual de empresas de todo o território nacional e com a rigorosa observação dos preceitos legais que regem os procedimentos licitatórios, estas mesmas aquisições puderam ser realizadas com um desconto de 42,64\% no ano de 2012 e de 37,64\% no ano de 2013. Desta forma é possível identificar e comprovar o princípio da economicidade, pressuposto fundamental do princípio da eficiência, na realização destes certames licitatórios.

Analisando a economicidade como um todo, no contexto da Administração Pública, Silva e Rovorêdo (2005), apresentam a seguinte definição:

\footnotetext{
A economicidade agrega outros conceitos, representando o gênero do qual a eficiência, eficácia e a efetividade são espécies. O ato do gestor público é econômico quando, ao mesmo tempo, é eficiente porque produz mais benefícios com menos recursos; é eficaz, porque consegue atingir as metas previamente estabelecidas nos planos, e adicionalmente, é efetivo, porque satisfaz às necessidades dos usuários/clientes, agregando resultado mensurável dos níveis de bem estar alcançados. (SILVA; REVORÊDO, 2005, p. 10 - grifo nosso)
}

Com isso, se tornam evidentes os princípios da eficiência e da eficácia, pois o objetivo maior da execução destes processos licitatórios foi a aquisição de móveis que atendessem a necessidade da Instituição e, por conseguinte, de seus administrados, e assim proporcionar à população um serviço de qualidade com o dispêndio mínimo de recursos financeiros, o tão aclamado bom uso do recurso público. 
Outro importante detalhe onde se pode verificar o princípio da eficiência é o pequeno número de itens cancelados, que sugere o interesse, por parte dos fornecedores, em contratar com a Administração Pública. Neste contexto, é importante destacar que a eficiência da pesquisa inicial de preços se torna fator determinante para a aquisição de um item, pois somente com a adequada estimativa de valor a ser pago pela Instituição acudirão interessados em fornecer o respectivo item, evitando assim a ocorrência de itens desertos, ou seja, sem interessados no fornecimento.

As impugnações foram respondidas de maneira ampla e transparente, não impedindo ou retardando a realização dos certames e demonstrando também o princípio da eficiência pelo fator tempo. As intenções de recurso, apresentadas apenas no pregão eletrônico 32/2013, foram afastadas pelo pregoeiro com a devida fundamentação legal, não havendo, assim, registro de recurso por parte dos licitantes, o que demonstra satisfação e conformidade dos licitantes para com os procedimentos adotados na realização dos certames, ou seja, com a lisura e a transparência dos atos praticados.

\subsection{DADOS COLETADOS INTERNAMENTE}

Quanto à pesquisa entre os servidores internos da Instituição, em resposta ao questionário encaminhado, foram as seguintes respostas tabuladas e que demonstram a presença do princípio da eficiência nestes certames licitatórios realizados pelo Campus Assis Chateaubriand.

Tabela 2 - Nível de aprovação dos pregões eletrônicos 42/2012 e 32/2013 entre os servidores internos

\begin{tabular}{|c|c|c|c|c|c|}
\hline \multirow[b]{2}{*}{ Questionamento } & \multicolumn{2}{|c|}{ Reprovação } & \multicolumn{2}{|c|}{ Aprovaçãa } & \multirow[b]{2}{*}{ Resultado obtido* } \\
\hline & Insatisfeito & $\begin{array}{c}\text { Parcialmente } \\
\text { Satisfeito }\end{array}$ & Satisfeito & $\begin{array}{c}\text { Muito } \\
\text { Satisfeito }\end{array}$ & \\
\hline $\begin{array}{l}\text { Qualidade dos móveis } \\
\text { adquiridos }\end{array}$ & 0 & 2 & 5 & 2 & $78 \%$ aprovaram \\
\hline $\begin{array}{c}\text { Atendimento às necessidades da } \\
\text { Instituição }\end{array}$ & 0 & 1 & 7 & 1 & $89 \%$ aprovaram \\
\hline Relação Custo-benefício & 0 & 0 & 9 & 0 & $100 \%$ Aprovaram \\
\hline
\end{tabular}

* Resultado obtido em relação aos formulários da pesquisa recebidos.

Fonte: elaborado pelo autor. 
Quanto ao princípio da transparência, o presente estudo questionou os servidores internos sobre a divulgação dos certames licitatórios. Neste quesito notou-se um certo descontentamento por parte destes. Os dados coletados apontam que o problema não está nas informações da licitação, onde se inclui o ato convocatório ou Edital, o termo de referência ou as demais informações acerca da realização dos certames, pois, conforme ilustra o gráfico 1 , em $64 \%$ das respostas analisadas, estas informações são vistas como suficientes.

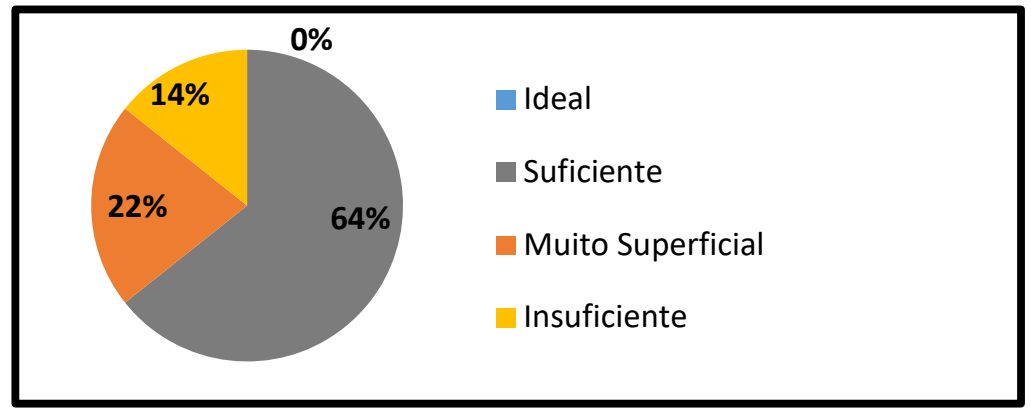

Gráfico 1 - Indicação do grau de satisfação quanto às informações da licitação Fonte: elaborado pelo autor.

Entretanto, a obrigatoriedade da publicação através do Diário Oficial da União divide ao meio as opiniões de sua eficácia. Em consonância com este entendimento, $86 \%$ dos participantes deste estudo indicaram, visando maior publicidade e transparência, que a Instituição também divulgasse, na página inicial do site da Instituição, a publicação dos certames licitatórios a serem realizados por ela, conforme gráfico 2.

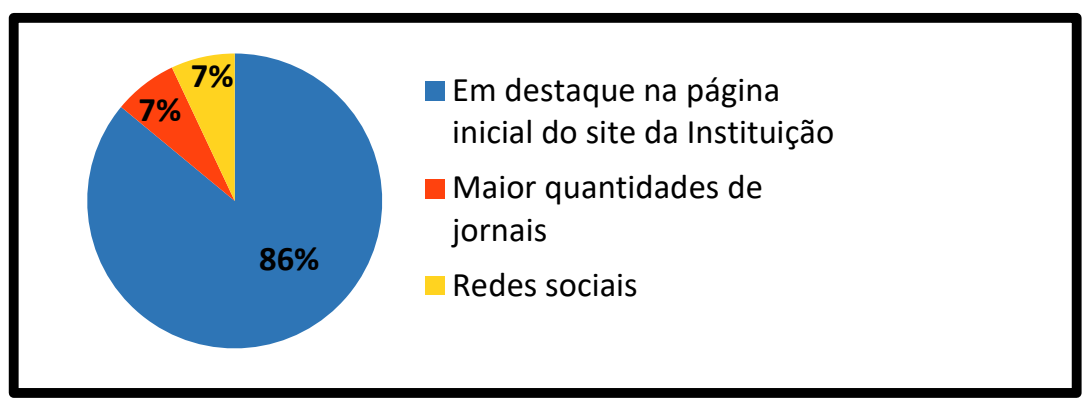

Gráfico 2 - Indicação de outras formas de divulgação dos certames licitatórios Fonte: elaborado pelo autor.

\subsection{DADOS COLETADOS ENTRE OS FORNECEDORES}

O questionário eletrônico foi encaminhado a todos os fornecedores que demonstraram interesse na participação dos certames licitatórios para o fornecimento de mobiliário em geral 
para os campi do Instituto Federal do Paraná nos anos de 2012 e 2013, respectivamente os pregões eletrônicos 42/2012 e 32/2013.

Estes questionários tiveram a finalidade de aprofundar a verificação acerca da observação dos princípios da eficiência, da economicidade e da transparência nestes certames licitatórios, conforme a visão do contratado ou interessado em contratar com a Administração Pública.

Houve o retorno de 20 questionários respondidos que formaram um banco de dados cujo resultado será apresentado a seguir.

A análise avaliativa do presente estudo junto aos fornecedores teve início com o princípio da publicidade, onde o objetivo primordial do questionamento foi conhecer a maneira pela qual o licitante tomou conhecimento da licitação. O gráfico 3 indica a análise das respostas obtidas.

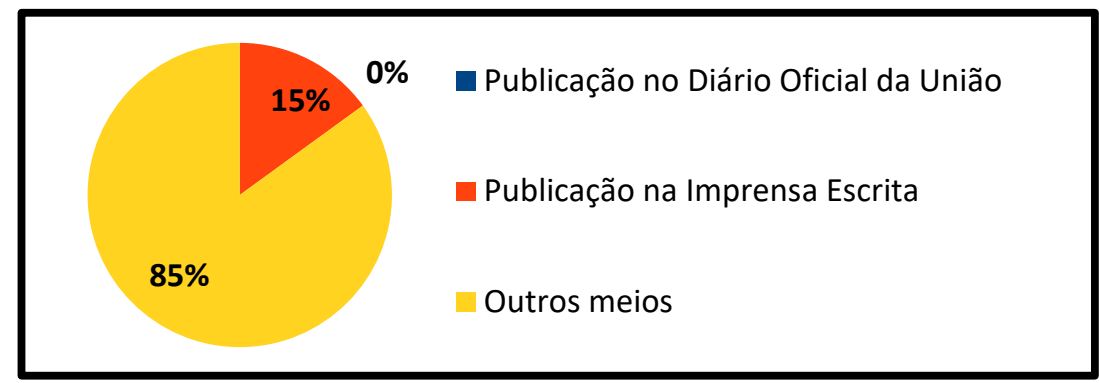

Gráfico 3 - Meios que os fornecedores tomaram conhecimento da licitação Fonte: elaborado pelo autor.

A análise deste questionamento aponta que nenhum dos consultados pelo questionário enviado tomou o conhecimento da licitação para a aquisição de móveis do Instituto Federal do Paraná através do Diário Oficial da União, somente $15 \%$ dos analisados tomou conhecimento pelos jornais, já, a grande maioria, $85 \%$ do universo pesquisado, tomou conhecimento através de outra ferramenta, possivelmente internet.

O gráfico 4 a seguir, demonstra, de forma quantitativa percentual, o grau de satisfação dos licitantes avaliados que participaram destes certames licitatórios em estudo. Para esta análise, foram escolhidos cinco indicadores avaliativos de maior importância, pois são os principais elos entre o pregoeiro e sua equipe de apoio com o licitante, considerados também o início da fase externa da licitação. 


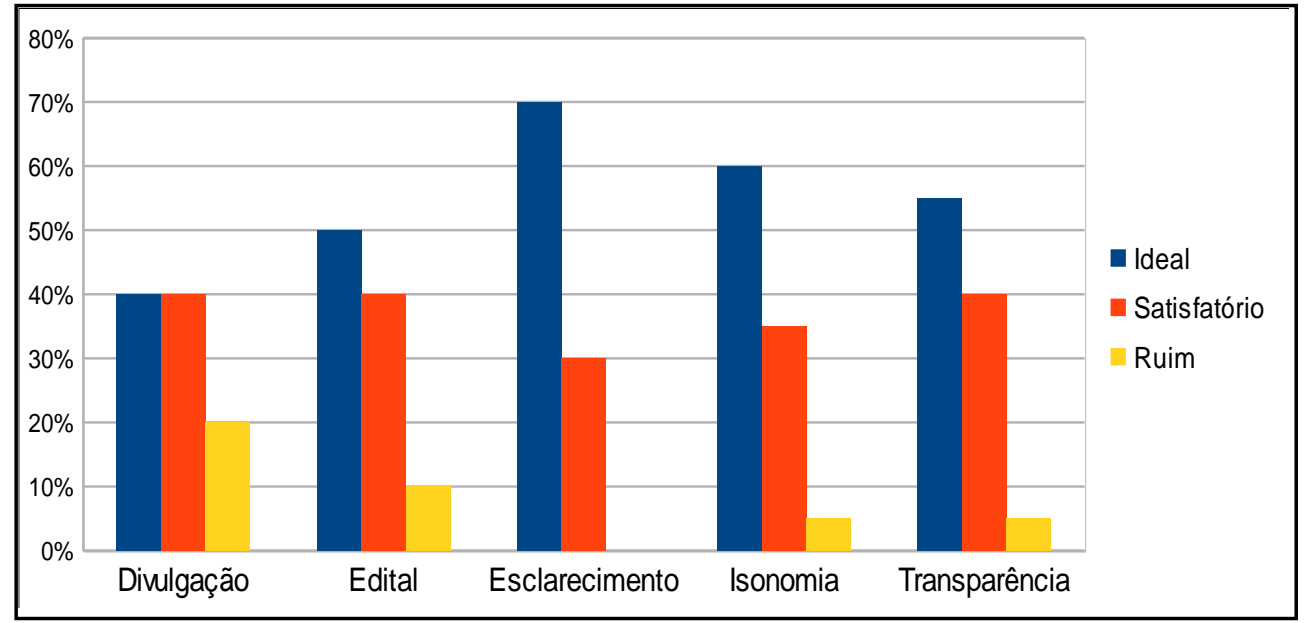

Gráfico 4 - Grau de satisfação dos licitantes em cinco fatores avaliativos Fonte: elaborado pelo autor.

O gráfico 4 apresenta a análise das respostas dos fornecedores para os cinco principais fatores da fase externa da licitação. Os dados coletados indicaram uma avaliação positiva para o edital com 50\% de aprovação, quanto aos esclarecimentos prestados, se constatou surpreendentes $70 \%$ de aprovação, por sua vez, quanto ao tratamento isonômico nestes pregões eletrônicos, houve uma aprovação de $60 \%$, e ainda, no que se refere à transparência demonstrada na realização dos certames, $55 \%$ das respostas analisadas foram positivas.

Considerando que, dentre estes quatro fatores apresentados, nenhum deles ultrapassou $10 \%$ de insatisfação, presume-se aqui um indicativo quanto à presença do princípio da eficiência nestes processos, pois, "O princípio da eficiência tem o condão de informar à Administração Pública, visando aperfeiçoar os serviços e as atividades prestados, buscando otimizar os resultados e atender o interesse público com maiores índices de adequação, eficácia e satisfação.” (IURCONVITE, 2010)

Entretanto, quanto à divulgação, nota-se um descontentamento por parte dos licitantes, visto que seu grau de insatisfação foi o mais elevado dentre os analisados, o que sugere a necessidade de aperfeiçoamento deste indicador.

Por fim, foi solicitado aos licitantes que estabelecessem uma nota geral de maneira a avaliar esses dois certames licitatórios realizados em 2012 e 2013 no Instituto Federal do Paraná, para aquisição de móveis em geral para todos os campi da Instituição. O resultado está exposto no gráfico 5. 


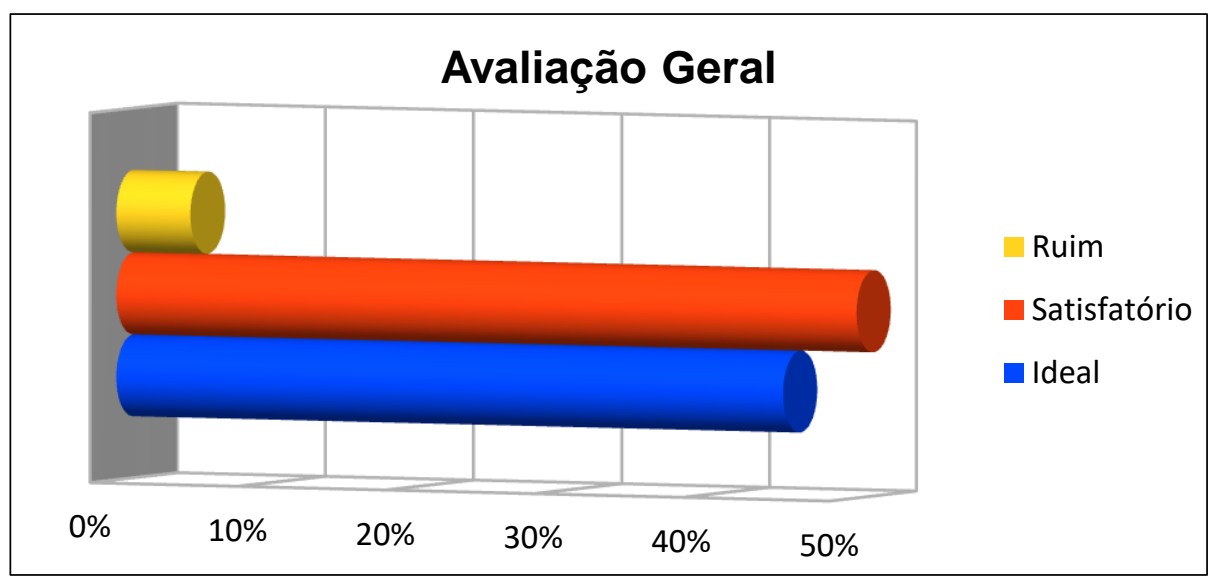

Gráfico 5 - Opinião geral dos licitantes quanto ao certame licitatório Fonte: elaborado pelo autor.

Conforme demonstra o gráfico acima, para $50 \%$ estes procedimentos licitatórios foram considerados satisfatórios e para $45 \%$ estes certames foram ideais. Somente $5 \%$ da amostra indicou que os certames analisados através deste estudo devem ser totalmente readequados. Concluindo a análise acima, tendo como base as respostas dos questionários encaminhados pelos licitantes participantes dos pregões eletrônicos para a aquisição de móveis em geral para o Instituto Federal do Paraná, houve êxito na realização dos dois certames licitatórios em análise, pois quando convocados a avaliar de forma geral a execução destes certames, 95\% das respostas indicaram como ideal ou satisfatório a realização destes pregões eletrônicos.

\section{CONSIDERAÇÕES FINAIS}

Considerando a importância das compras públicas para a gestão administrativa de qualquer Instituição pública, o presente trabalho demonstrou que o Instituto Federal do Paraná, especificamente o Campus Assis Chateaubriand obteve êxito quanto à realização dos pregões eletrônicos quando se refere à observância dos princípios da eficiência, da economicidade e da transparência.

O princípio da eficiência pôde ser demonstrado em vários aspectos deste estudo. A participação dos atores envolvidos nestas aquisições, através de respostas aos questionamentos realizados por meio de formulário eletrônico, se traduziu em uma avaliação satisfatória para este princípio basilar das contratações públicas. O maior indicador da eficiência destes certames licitatórios foi a comprovação do princípio da economicidade, demonstrada através do estudo comparativo entre os valores estimados para as referidas 
aquisições e o real valor da contratação, que estabeleceu um desconto de 42,64\% em 2012 e $37,64 \%$ em 2013.

O princípio da economicidade foi o parâmetro estabelecido para avaliar a eficiência destes pregões eletrônicos. A economia gerada se deu inicialmente pela opção da modalidade escolhida para a realização dos certames licitatórios, pregão eletrônico, ou seja, a simples observância ao preceito legal foi também um indicador da existência deste princípio. Conforme demonstrado na Tabela 2, a relação custo-benefício foi aprovada pela totalidade dos gestores internos como sendo satisfatória, solidificando assim a comprovação do princípio da eficiência através do princípio da economicidade.

O princípio da transparência foi avaliado sob dois pontos de vista. Primeiramente pelo ponto de vista dos servidores internos da instituição e, posteriormente, pelo ponto de vista dos licitantes, ou seja, todos os atores que, de alguma forma, participaram destes procedimentos licitatórios em análise.

Considerando a visão dos servidores internos da Instituição que aceitaram participar deste estudo, houve a avaliação da opinião destes quanto à forma como são divulgados os certames licitatórios da Instituição, e também sobre o grau de satisfação destes servidores quanto às informações da licitação, aqui incluídos, o ato convocatório ou Edital, o termo de referência e as demais informações acerca da realização dos certames, onde, sob esta ótica, $64 \%$ dos servidores se disseram satisfeitos.

Já, sob o ponto de vista dos licitantes que se prontificaram a responder o formulário eletrônico encaminhado, principais avaliadores deste princípio, obteve-se um resultado bastante significativo, que permite afirmar certamente que o princípio da transparência se fez presente nos certames licitatórios analisados por este estudo de caso. Conforme indicado no gráfico 4, o fator transparência foi considerado ideal em $55 \%$ e satisfatório em $40 \%$ das respostas coletadas. Desta forma, $95 \%$ das respostas analisadas indicaram que o princípio da transparência foi considerado, no mínimo, satisfatório.

Finalizando o presente estudo de caso, um princípio merece atenção especial quanto a sua aplicabilidade. Observou-se, através da análise dos questionários recebidos, que nenhum dos licitantes tomou conhecimento destes pregões eletrônicos pela publicação no Diário Oficial da União, apenas 3 licitantes tomaram conhecimento destes pregões eletrônicos através de publicação na imprensa escrita e a grande maioria,17 licitantes, $85 \%$ dos questionários respondidos, informaram ter tomado conhecimento destes certames licitatórios através de outro tipo de publicação. Sendo assim, diante da análise destes dados, verifica-se a necessidade da realização de novos estudos que permitam conhecer, de modo mais ForSci.: r. cient. IFMG, Formiga, v. 6, n. 1, e00275, jan./jun. 2018. 
aprofundado, o perfil do licitante quanto a maneira pela qual toma ciência dos processos licitatórios.

De acordo com Barbosa (2011), para que ocorra um procedimento licitatório sem máculas é de substancial importância que ele tenha o máximo de publicidade possível. Diante desta afirmação, o princípio da publicidade deve ser reavaliado na instituição. Esse pressuposto ganha força quando se confronta com os percentuais obtidos entre os servidores da instituição, onde $86 \%$ destes acreditam que os certames licitatórios deveriam ser também publicados em destaque na página inicial do site da Instituição.

\title{
ECONOMICITY, EFFICIENCY AND TRANSPARENCY IN PUBLIC PURCHASES BY ELECTRONIC PREGNANCY: CASE STUDY OF ELECTRONICS PROSPECTS 42/2012 AND 32/2013 MADE BY IFPR - CAMPUS ASSIS CHATEAUBRIAND
}

\begin{abstract}
This article discusses the concern with public expenditures, mainly with the basic principles of economicity, efficiency and transparency, at the Federal Institute of Paraná, specifically focusing on two bidding competitions, Electronic Pregnancy modality - Price Registration System (SRP). The acquisition of furniture in general for the various Campuses of the Institution, carried out by IFPR - Campus Assis Chateaubriand in 2012 and 2013. Through documentary data and field research, carried out by means of electronic questionnaire sent to the institution's internal managers and involved bidders in these events, the purpose was to verify the existence of these basic principles in the two events listed. The principle of costeffectiveness was demonstrated through a comparative study between the estimated values for these acquisitions and the real value of the contracting, which established a discount of $42.64 \%$ in 2012 and $37.64 \%$ in 2013 . It was also observed that $85 \% \%$ of suppliers took notice of these two electronic forums by means other than the Official Gazette and Newspapers, and the principle of publicity deserves a re-evaluation by the institution. In general, it is possible to evaluate in a positive way the achievements of these electronic preambles on the principles listed.
\end{abstract}

Keywords: Electronic trading. Economicity. Efficiency. Transparency. Public purchases.

\section{REFERÊNCIAS}

ARAÚJO, L. M.; RODRIGUES, M. I. A. A relação entre os princípios da eficiência e da economicidade nos contratos administrativos. Revista do Serviço Público, Brasília, v. 63, n. 1, p. 43-62, jan./mar. 2012. 
BARBOSA, R. C. Licitação Pública: noções gerais do Dever de Licitar. Revista Unifacs, n. 139, 2012. 17 p. Disponível em: <http://www.revistas.unifacs.br/index.php/redu/article /view/1892. Acesso em: 02 out. 2014.

BERNARDI, L. A. Manual de Empreendedorismo e gestão: fundamentos, estratégias e gestão. 2. ed. São Paulo: Atlas, 2012.

BRASIL. Constituição (1988). Constituição da República Federativa do Brasil. Brasília, DF: Senado, 1988.

Lei no 8.666, de 21 de junho de 1993. Regulamenta o art. 37, inciso XXI, da Constituição Federal, institui normas para licitações e contratos da Administração Pública e dá outras providências. Disponível em: <http://www.planalto.gov.br/ccivil_03/leis/ 18666cons.htm>. Acesso em: 02 out. 2014.

Lei $\mathbf{n}^{\mathbf{0}} \mathbf{1 0 . 5 2 0}$, de 17 de julho de 2002. Institui, no âmbito da União, Estados, Distrito Federal e Municípios, nos termos do art. 37, inciso XXI, da Constituição Federal, modalidade de licitação denominada pregão, para aquisição de bens e serviços comuns, e dá outras providências. Disponível em: <http://www.planalto.gov.br/ccivil_03/leis/2002/110520.htm>. Acesso em: 02 out. 2014.

Decreto no 3.555, de 08 de agosto de 2000. Aprova o Regulamento para a modalidade de licitação denominada pregão, para aquisição de bens e serviços comuns. Disponível em: <http://www.planalto.gov.br/ccivil_03/decreto/d3555.htm>. Acesso em: 02 out. 2014.

Decreto no 5.450, de 31 de maio de 2005. Regulamenta o pregão, na forma eletrônica, para aquisição de bens e serviços comuns e dá outras providências. Disponível em: <http://www.planalto.gov.br/ccivil_03/_ato2004-2006/2005/decreto/d5450.htm>. Acesso em: 02 out. 2014.

Decreto $\mathbf{n}^{0}$ 5.504, de 05 de agosto de 2005. Estabelece a exigência de utilização do pregão, preferencialmente na forma eletrônica, para entes públicos ou privados, nas contratações de bens e serviços comuns, realizados em decorrência de transferências voluntárias de recursos públicos da União, decorrentes de convênios ou instrumentos congêneres, ou consórcios públicos. Disponível em: <http://www.planalto.gov.br/Ccivil_03/ _ato2004-2006/2005/Decreto/D5504.htm>. Acesso em: 02 out. 2014.

CHIAVENATO, I. Introdução à Teoria Geral da Administração: na administração das organizações. Edição Compacta. 3. ed. Rio de Janeiro: Elsevier, 2004.

DI PIETRO, M. S. Z. Direito administrativo. 10. ed. São Paulo: Atlas, 1998.

FIGUEIREDO, L. V. Curso de direito administrativo. 7. ed. São Paulo: Malheiros Editores, 2004.

IURCONVITE, A. dos S. A concretização dos direitos sociais: breves apontamentos. Âmbito Jurídico, Rio Grande, XIII, n. 74, mar 2010. Disponível em: <http://www.ambitojuridico. com.br/site/index.php/\%3Fn_link\%3Drevista_artigos_leitura\%26artigo_id\%3D12559\%26rev 
ista_caderno\%3D28?n_link=revista_artigos_leitura\&artigo_id=7277\&revista_caderno=9>. Acesso em: 30 abr. 2018.

LAKATOS, E. M.; MARCONI, M. de A. Fundamentos de metodologia científica. 5. ed. São Paulo: Atlas, 2003.

MORAES, A. de. Constitucionalização do Direito Administrativo e princípio da eficiência. In: FIGUEIREDO, C. M.; NÓBREGA, C. (Orgs.). Administração Pública: direito administrativo, financeiro e gestão pública: práticas, inovações e polêmicas, 2002 . p. 25-54.

PEREIRA, L. C. B. G.; SPINK, P. K. Reforma do Estado e administração pública gerencial. Rio de Janeiro: FGV, 2006.

SILVA, C. A. T.; REVORÊDO, W. C. Economicidade da Gestão Pública Municipal: um estudo das decisões do tribunal de contas do Estado de Pernambuco. Revista Universo Contábil, Blumenau, v. 1, n. 2, p. 9-22, maio/ago. 2005.

STADLER, A. Fundamentos da Administração: curso técnico em logística. Caderno e-tec Brasil. Curitiba: IFPR, 2010.

YIN, R. K. Estudo de caso: planejamento e métodos. 5. ed. Porto Alegre: Bookman, 2015.

\section{DADOS DOS AUTORES}

\section{Helton Jaques Albiero}

E-mail: helton.albiero@ifpr.edu.br

Currículo Lattes: http://lattes.cnpq.br/5425305954343181

Mestrando em Sustentabilidade (UEM/IFPR). Especialista em Gestão Pública pelo Instituto Federal do Paraná (IFPR). Graduado em Ciências Econômicas pela Universidade Estadual do Oeste do Paraná (UNIOESTE). Atualmente é coordenador administrativo do Instituto Federal do Paraná - Campus Assis Chateaubriand.

\section{Marcelo Rodrigues da Silva}

E-mail: marcelo.silva@ifpr.edu.br

Currículo Lattes: http://lattes.cnpq.br/7336846339310646

Mestre profissional em Planejamento e Governança Pública pela Universidade Tecnológica Federal do Paraná (UTFPR). Especialista em Gestão Empresarial pela Universidade Federal do Paraná (UFPR). Graduado em Administração e Tecnologia em Eletrônica. Atualmente é discente do programa de Pós Graduação stricto sensu em Planejamento e Governança Pública da UTFPR e administrador e professor orientador de TCC do IFPR. 